\title{
Quantifying tropical wetlands using field surveys, spatial statistics and remote sensing
}

\begin{abstract}
Tropical wetlands support high biodiversity and ecological services, but in most areas they suffer from a paucity of baseline data to support management. We demonstrate how modern technology can be used to develop ecological baseline data including, landuse/landcover, water depth, water quality, lake-level fluctuation, and normalized difference vegetation index (NDVI). For the first time we quantified and mapped these metrics for the Paya Indah Wetlands, Malaysia using the new high-spatial-resolution World View 2 imagery. Landuse/landcover classifications were validated by field visits and visual interpretation of the imagery. NDVI was extracted based on red and near infra-red 2 bands. Topo to Raster method was used for interpolation of water depths. Annual mean of a water-quality index and annual water-level fluctuation of lakes were interpolated across lakes using the inversedistance weighting method. Qualitative and quantitative accuracy assessment of classification ( $75 \%$ overall accuracy, user's accuracies ranged from $60 \%$ to $90 \%$ and producer's accuracy ranged from $60 \%$ to $97 \%$ ) was promising and clearly illustrated that World View 2 imagery can yield fast and reasonably precise identification of ecosystem characteristics for ecological baselines.
\end{abstract}

Keyword: Interpolation; Landuse; Landcover; Malaysia; NDVI; Paya Indah Wetlands 